\title{
ЧЕЛОВЕЧЕСКИЙ КАПИТАЛ, АКТУАЛЬНОСТЬ ЕГО ФОРМИРОВАНИЯ В НАСТОЯЩЕЕ ВРЕМЯ
}

\section{HUMAN CAPITAL, THE RELEVANCE OF ITS FORMATION AT THIS MOMENT \\ V. Betanov}

Summary. The article substantiates the defining role of education in the formation of human capital. The fallacy of the policy of deideologization of society and education is argued. The comparative characteristics of the Soviet and modern education systems are carried out. The relevance of the formation of students' awareness of the sense of ownership of their knowledge and the ability to manage them is substantiated. The urgency of centralized regulation of training programs, distribution of specialists is emphasized. The fallacy of the system, society, and economy's lack of demand for high achievements of science and education as the fundamental principles of human capital is emphasized. To improve its quality, the necessity of conducting elective classes in secondary and school is justified to familiarize students with the specifics of different specialties in order to choose a university, specialty. For those who have studied at the expense of budgetary funds, the introduction of material liability is proposed for refusing to work in the specialty.

Keywords: capital, economy, person, system, education, science, intelligence, teacher, investment, consumer, ideology, children, schoolchildren, reforms, speciality, accumulation, standards, career guidance, elective.

\author{
Бетанов Владимир Магометович \\ К.э.н., дочент, Новосибирский государственный \\ педагогический университет \\ v.betanov@yandex.ru
}

Аннотация. В статье обосновывается определяющая роль образования В становлении человеческого капитала. Аргументируется ошибочность политики деидеологизации общества, образования. Проводится сравнительная характеристики советской и современной систем образования. 0босновывается актуальность формирования у учащихся осознания чувства собственника своих знаний и умения ими управлять. Подчеркивается актуальность централизованного регулирования программ подготовки, распределения специалистов. Подчеркивается ошибочность невостребованности системой, обществом, экономикой высоких достижений науки, образования как первооснов человеческого капитала. Для улучшения его качества обосновывается необходимость ведения факультативных занятий в средней школе для ознакомления учащихся со спецификой разных специальностей с целью выбора вуза, специальности. Предлагается введение материальной ответственности для обучившихся за счет бюджетных средств в случае отказа от работы по специальности.

Ключевые слова: капитал, экономика, человек, система, образование, наука, интеллект, учитель, инвестиции, потребитель, идеология, дети, школьники, реформы, специальность, накопление, стандарты, профориентация, факультатив.

В настоящее время исследователи едины в том, что в последние годы важнейшей проблемой становится все более снижающийся уровень знаний, образования - первоосновы человеческого капитала [2] [3]. Нарастает тенденция снижения уровня интеллекта трудовых ресурсов, их знаний, инструментария управленческого труда в целом. Мы разделяем точку зрения, согласной которой причиной тому является внедрение в современной России «Болонской» системы образования. В результате одна из лучших в мире систем образования, десятилетиями формировавшаяся в нашей стране, заметно сдала свои позиции. В то же время, кризисы последних лет, пандемия показывают, что трудности формирования рыночных отношений, предъявляют более жесткие требования к качеству человеческого капитала. Новые условия предопределяют необходимость постоянного его совершенствования. Это непременное условие поступательного развития экономики. 
Важнейшей характеристикой человеческого капитала является его результативность в решении экономических задач [4]. В этом её общность с категорией «капитал» как «самовозрастающей стоимости». Известно, что для «самовозрастания» человеческого капитала важны здравоохранение, свобода миграции рабочей силы, достоверная информация. При этом надо признать, что образование является фундаментом, отправной точкой для формирования индивида, начиная с начальной школы. Именно на этом уровне закладывается основа формирования человека как инноватора.

В настоящее время не утихают дискуссии вокруг советской системы образования. При этом мнения противоположные. Следует выделить признание советской системы образования со стороны зарубежных ученых и политиков. Так, в свое время Д. Кеннеди говорил: «Советское образование - лучшее в мире. Мы должны многое из него взять. СССР выиграл космическую гонку за школьной партой» [5]. По мнению Р. Рейгана, «самое мощное оружие русских - это их образование» [6]. В 1980-х годах Китай реформировал свою систему образования по образцу советской, получив высокие результаты. В 2019 году Великобритания объявила, что переходит на использование всей вертикали советской системы образования.

С другой стороны, существует иное мнение. Например, Г. Греф утверждает о том, что «нужно менять модель образования от детских садов до вузов, что нельзя воспроизводить старую советскую, абсолютно негодную систему образования, нельзя напихивать в детей огромное количество знаний» [7]. А. Чубайс А. придерживается аналогичной точки зрения, говоря, что «ненавидел свою школу, которая была с продвинутым военно-патриотическим воспитанием». Согласно мнения Чубайса образование должно быть платным уже после третьего класса и приносить прибыль. Д. Ливанов согласен с предыдущими авторами, утверждая, что: «готовить надо не разработчиков технологий, а специалистов, которые могут адаптировать заимствованные технологии» [8].

Современная реформа образования в России по форме, цели и результатам напоминает реформы образования в СССР в первой половине 1960-х годов. С 1967 года ожидался дефицит рабочих рук («демографическая яма»). Это было «первое эхо» Великой отечественной войны. Дети, родившиеся в 1945 году и позже в 1967 году должны были получить образование, стать специалистами, но их было мало. По этой причине с 1963 года учащихся со средних классов, начали обучать рабочим профессиям. В 1966 г. выпускными были 10-е и 11-е классы. Выпускникам вместе с аттестатами вручались удостоверения рабочих профессий. Моло- дые люди, не поступившие в том году и позже в вузы, шли работать по полученной в школе профессии. Возможно, что современные реформы задуманы с такой же целью. Необходимо решать проблему «русского креста» 1990-х годов, предопределившего дефицит рабочей силы наших дней.

Во второй половине 1980-х гг. образование в нашей стране подвергалось критике, якобы, оно «заидеологизировано», что "учителя не отвечают требованиям времени», «дипломы советских вузов не признаются за рубежом» - это был основной аргумент. Но он уже тогда был несостоятелен. Невозможно отрицать, что на протяжении 1960-х и до середины 1980-х годов из стран Азии, Африки, Европы ежегодно в США приглашались 55-60 тысяч выпускников советских вузов на самые высокооплачиваемые должности.

С уверенностью можно сказать, что причиной «непризнания» советских дипломов была экономика. Вся вертикаль западной системы образования обходилась в 10-15 раз дороже, чем в СССР. При этом вузы нашей страны готовили специалистов-универсалов. С ними трудно было конкурировать выпускникам зарубежных вузов. Выходило, что значительные денежные расходы оказывались напрасными. Этот фактор стал причиной непризнания дипломов советских вузов, хотя их обладателей продолжали приглашать.

Реформа образования имеет свою историю. В 1980-е годы в школах, вузах началось активное внедрение всевозможных технических средств обучения (ТСО). Для ответов на вопросы преподавателей не нужны были слова, связная речь. Надо было уметь нажимать нужные кнопки, чтобы на экранах высвечивались цифры, указывавшие на ответы в соответствующих сборниках. Задавать другими словами этот же вопрос было нельзя, что ставило учащихся в трудное положение, поскольку их готовили думать и отвечать стандартно. Вскоре эксперимент закрыли.

Несколько позже в начальной школе, первоклассникам, запретили задавать домашние задания, якобы дети «перегружены». Запретили ставить оценки, чтобы «не травмировать психику детей». Однако этих же детей с 3-4 лет(?!) родители определяли во всевозможные секции художественной, спортивной гимнастики, плавания, хоккея, футбола и т.д., где нагрузки несопоставимые со школой, что проходило мимо внимания «реформаторов».

По факту детей с первого класса не научили учиться. Наоборот, приучили к безделью, безответственности. В средних и старших классах с появлением всевозможных «интерактивных» досок эти качества только умно- 
жились. На чудо-доске появилась красивая картинка, с её исчезновением которой и появлением другой, еще более красивой, бесследно исчезала память о первой картинке. Быстрая сменяемость красивых картинок в голове ребенка не формировала какую-нибудь целостность. В результате среднее образование, как фундамент человеческого капитала, оказался рыхлым. Выпускники школ в большинстве своем крайне слабо подготовлены для обучения в вузе.

В начале 1990-х годов был провозглашен лозунг о реформировании общественного сознания посредством «деидеологизации» среднего и высшего образования, армии, чем отвергались все советские идеалы, ценности. Доминировала идеология, согласно которой образование необходимо подвести к требованиям рыночной экономики, что «патриотизм - последнее прибежище негодяя» и т.д. Еще вчера «убежденные коммунисты» говорили о лживости коммунистической идеологии. В своих политических посылах опирались на западных теоретиков. По существу это было насаждение чуждой России западной идеологии. Такая деидеологизация означала привить молодежи, народу России либеральные ценности потребительского общества. Этому способствовал длинный ряд «вдруг прозревших советологов»: Яковлев А.Н., Коротич В.А., Волкогонов Д.А. и другие очень старались «очернить» историю СССР.

Громко прозвучал лозунг «Обогащайтесь!» (Б.Н. Ельцин). «Деньги должны были стать единственной наичиональной идеологией (А. Козырев). Эти простые заявления, стали ориентирами для молодежи, сформировав у неё товарно-денежный фетишизм.

Деидеологизация усугубилась реформами программ федеральных образовательных стандартов (ФГОС), введенных в 2000 году. С их введением связан определенный период времени. Школы, вузы наделили правом самостоятельно составлять программы обучения детей, студентов. Содержание программ всецело зависело от морали, убеждений их составителей. Результат оказался плачевным. Учащиеся потеряли ориентиры в потоке разноплановой информации, интерес к обучению, переместив сферу своих интересов в сторону компьютеров, планшетов, смартфонов.

С 2010-х годов в вузах начались бесконечные, по 2-3 раза в год, «совершенствования» учебных программ. Об их внедрении речи не было. Поступал приказ о срочном совершенствовании «усовершенствованной вчера программы» и необходимости отчитаться. Нужны были отчеты о выполнении. В результате из вузов увольнялись опытные преподаватели, учебные часы которых распределялись между оставшимися. Вдвое и более возросли нагрузки, а зарплата сократилась в обратной пропорциональности. Так получилось потому, что реформой образования занимались чиновники, никогда не работавшие в сфере образования. Опытные школьные учителя и преподаватели вузов до составления программ не допускались. По состоянию на 2021 год об «усовершенствованных учебных программах» никто не вспоминает.

Снижение уровня образования началось с недостаточного финансирования. В 1992 г. после выхода Закона «Об образовании», была поставлена задача на децентрализацию образования и сокращение расходов на неё. В результате к началу 2020-х годов Россия по этому показателю опустилась на 98 место среди стран мира. Практически стало нормой, что в школе зарплаты уборщицы и учителя сравнялись. В вузах соотношение зарплат между руководством вуза и «рядовыми преподавателями» в последние годы составляет 1:20-35 и более раз. Это стало нормой. На всю страну «прогремели» зарплаты ректоров вузов г. Екатеринбурга [9]. Аналогичные тенденции можно наблюдать во всех вузах страны.

Активная фаза реформы образования началась в 2003 г. с подписанием Болонской декларации. Она заменила научно-фундаментальный подход к образованию «компетентностным», согласно которому молодой специалист должен получить некий набор узкопрофильных знаний, использованием которых «молодой специалист сможет более или менее ориентироваться в существуюших, устоявшихся рамках своей профессии, но он не сможет изменять, усовериенствовать его» (А. Фурсенко). Он же: «Недостатком советской системы образования была попьтка формировать человека-творича, а сейчас задача заключается в том, чтобы взрастить квалифицированного потребителя, способного квалифицированно пользоваться результатами творчества других» [10]. Однако индивид, воспитанный на философии потребительства, никогда не озадачится проблемой производства.

Фурсенко также заявлял «избыточном количестве учителей» в нашей стране. Он выдвигал идею по ликвидации педагогических вузов, утверждал, что «в школу придут инженеры, выпускники отраслевых вузов и будут преподавать» (?!).

Опыт внедрения ЕГЭ показал, что он себя никак не оправдал. Признать это означает нести ответственность за провалы в сфере образования. Хотя косвенное признание этого факта имеют место. Например, осознанием того, что знаний школьников будет недостаточно для преодоления барьера выпускных экзаменов, ввели 
ЕГЭ. Этих знаний будет недостаточно для поступления в вуз посредством вступительных экзаменов. Выход нашли - учащихся теперь «натаскивают» по предметам, которые нужны в вузе. Теперь ребята в вуз не посmyпают, их туда принимают на основе показателей ЕГЭ.

В 2011 г. в защиту ЕГЭ было сказано, что «60\% выпускников школ отдаленных уголков страны были приняты в ведущие столичные вузы» (В. Путин). Это соответствует действительности. Примерно столько же было принято и в известные региональные вузы. Тогда желающих поступить в вузы было 80\%. Однако, это слабый аргумент в пользу ЕГЭ. На первой же сессии треть и более из принятых в вуз становятся кандидатами на отчисление. Конечно, бывают исключения, но их крайне мало.

Почему для «глубинки» нельзя выделить цуелевые места, чтобы там организовать конкурсные экзамены для более подготовленных ребят? Такой подход будет гарантировать и возвращчение специиалистов обратно. Проблема нехватки специалистов, в частности учителей, врачей, агрономов и др. будет решена.

По этому поводу В.А. Садовничий (ректор МГУ) сказал: «Да, мы можем сказать, что ЕГЭ стал соииальным лифтом, но в этот лифт не помещзается «иирота» икольного образования. Существующая система ЕГЭ не способствует «взращиванию» и выявлению самородков - будущих великих учёных. ... Если мы начинаем так сужать их подготовку, то Колмогорова или Келдыша не будет» [11].

В 2021 году количество желающих поступать в вуз было всего 43\%. Вузам не хватает студентов. Налицо падение популярности высшего образования. Не способствуют росту престижа высшего образования и многочисленные (до 70-80\%.) примеры получения дипломов вузов, но работы по другой специальности. Надо признать и то, что полученные ради «корочек» знания в массе своей не соответствуют критериям высшего образования.

Педагогические, экономические и юридические вузы относятся к числу наименее затратных. В 2019 году прием на бюджетные места в педагогические вузы был увеличен до 73 тысяч человек. На их обучение было выделено около 5 млрд. руб. Из них до окончания вуза доходят около $60 \%$, а работать по специальности идут 30\% выпускников [12]. Это означало, что 3,5 млрд. руб. были потрачены неэффективно. К тому же тысячи молодых людей зря потратили время, а в школах образовалась острая нехватка учителей по ряду дисциплин.
В 2021 году вузам выделено более 588 тыс. бюджетных мест. Из них большая часть приходится на педагогические вузы. При этом продолжает нарастать дефицит учителей в школах. По прогнозам к 2029 году нехватка школьных учителей составит 190 тыс. человек [13].

На наш взгляд, причина нехватки учителей не только в низкой зарплате, а в системе приема в вуз. На основании ЕГЭ выпускникам школ можно подавать документы в 5 вузов на 20 специальностей, т.е. куда-нибудь да примут. Считаем, этим ребят лишили конкретной цели для получения специальности. Сомнительно, что принятые в вуз по этому принципу, будут с желанием учиться, а потом еще и работать по этой специальности.

На наш взгляд, для возвращения образованию роли первоосновы человеческого капитала, в школе по-другому необходимо проводить профориентацию, например, в форме факультативных занятий. Её следует начинать с 7-8 класса посредством коротких бесед о профессиях. Можно начинать с того, что школьникам 7-9-х классов поручать организацию игр с детьми младших классов. Для встреч со старшими школьниками следует приглашать состоявшихся в профессии специалистов. Если у ребенка появится интерес, например, к профессии врача, то нет никаких проблем для того, чтобы организовать учащимся в 10-11 классах «дежурство» в медицинском учреждении. Побыть санитаром или кем-нибудь еще один-два раза в месяц по 3-4 часа будет необременительно для школьников. На протяжении 1-2 лет «практикант» сможет прочувствовать внутреннее содержание профессии. Если за это время ему не разонравится профессия медика, то он осознано поступит в медицинский вуз. Быть ему хорошим врачом.

То же самое относится и к профессии учителя, агронома, ветеринара и др. Учащимся 10-11-х классов можно доверять проводить уроки по разным дисциплинам в «средних» классах, конечно, под контролем заинтересованного учителя. Автор прошел эту форму «введения в специальность» под руководством очень умного, заинтересованного учителя. Такая практика покажет внутреннюю структуру педагогического труда. Не исключено, что откроет путь к профессии учителя. А педсовет школы может решить вопрос о рекомендации его в педагогический вуз, куда следует принимать детей преимущественно по рекомендациям педагогических советов школ. Такой студент и выпускник педагогического вуза не будет сомневаться в правильности выбранной профессии.

Может случиться и такое, что не пойдет работать по полученной профессии. Бывают же исключения: семейные обстоятельства, болезнь, муж военный и др. Эти факторы необходимо учитывать. А в целом нужна поли- 
тическая воля для принятия соответствующего решения. Вусловиях приема следует отметить, что после окончания вуза необходимо отработать по специальности не менее трех лет. В противном случае придется возвращать бюджетные средства, а это более 70\% бюджета отрасли образования. Этим можно уменьшить попадание, в частности в педагогический вуз случайных людей. Сэкономленные таким образом средства можно направить в пользу роста зарплат работающих в школе по специальности и для роста стипендий студентам педагогических вузов. По расчетам этой мерой можно утроить зарплаты и стипендии. Можно не сомневаться, что при таком (подобном) подходе значительно вырастет конкурс в педагогические вузы, в том числе среди «целевиков».

Принципиально важно понимать, что главную роль в становлении человека, специалиста играет учитель. Он с самого раннего детства, в школе, вузе ведет человека к специальности. Вначале учитель, и только потом инженер, строитель, государственный чиновник, предприниматель и др.

В настоящее время необходимо также признать, что главным содержанием теории человеческого капитала является признание человека объектом капитальных вложений. Многократно доказано, что инвестиции в человека более прибыльные, чем в любую другую отрасль. Об этом говорят результаты достижений НТР, НТП последних лет, которые осуществлялись специалистами-творцами. Правда и то, что срок оборачиваемости вложений в образование и науку более длительный, чем в бизнес. Но Россия, её экономика находятся в таком состоянии, что необходима долгосрочная стратегия.

А в последние годы из-за недофинансирования образования и науки вдвое сократилось число желающих поступать в аспирантуру. В 2021 году в вузы изъявили желание поступать немногим более $40 \%$ выпускников школ. В порядке сравнения, в 2020 году их было около $50 \%$, а в 2010 году - $80 \%$.

В настоящее время всем очевидно, что тенденция снижения уровня человеческого капитала России продолжается практически по всем показателям: здоровья, уровня интеллекта, морали, нравственных качеств, отсутствие идеалов, жизненных ориентиров, бездуховность и т.д. Повторимся, что накопление человеческого капитала начинается с самых ранних лет жизни. Если в детском садике, начальной школе не научить ребенка что-то делать полезное, чтобы он чувствовал за это ответственность, то в средних и старших классах его уже невозможно переобучить.

В классическом определении накопление капитала (капитализм как процесс) — это постоянно повто- ряющийся проиесс превращчения части прибыли в дополнительные факторы производства для получения дополнительной прибыли. Применительно к человеку это определение следует понимать так: накопление человеческого капитала - это возможность и желание человека к самовоспрочзведению в расширенном масштабе, т.е. к воспроизведению научных знаний, технологий, умений более высокого уровня [14].

Таким образом, образование и наука - главный компонент в структуре человеческого капитала. В современных условиях осознание этого факта даст значительные преимущества тому, кто будет реализовывать его на деле. В России необходимо восстановить былую роль образования всех уровней. Необходимо также возобновить централизованное регулирование подготовки специалистов по всем отраслям.

Дети, родившиеся в XXI веке, ничем не отличаются от детей предыдущих столетий. До 9-10-летнего возраста понятия НТР, НТП, цифровизация, передовые технологии и т.п. для них не более, чем сотрясание воздуха. Детям этого возраста никакая интерактивная доска не заменит живого учителя с мелом в руке у черной (зеленой) доски, на которой он выводит буквы, цифры, проговаривая свои действия и приглашая детей повторять с ним все действия. Что с букв «а, б, в... » начинаются слова... ., что за цифрами 2, 3 и др. стоят два, три добрых (недобрых) поступка, в которых ребенка надо научить видеть себя, своих одноклассников, свою (их) роль. За словами, цифрами ребенка надо научить видеть какой-то смысл, нечто конкретное. Этим подходом у ребенка точно будет развиваться пространственное мышление.

Таким образом, главная проблема науки и образования, как первоосновы человеческого капитала, заключается не столько в недостаточности финансирования, сколько в невостребованности их системой, обществом, экономикой. В результате утеряны целые отрасли и производства высоких технологий. Их возрождение возможно исключительно на основе создания новых высококлассных технологий, соответствующих требованиям времени, и, самое главное - формирования адекватного человеческого капитала.

Для этого в средних классах школы и старше детей следует дозировано втягивать в современные цифровые технологии. В 10-11-м классах школы, гимназии на условиях добровольности, факультативно ввести практику «введение в специальность». Человека с самого раннего детства необходимо сделать объектом капиталовложений по все вертикали получения образования. Только при таком походе возможно возрождение науки, образования как основы становления человеческого капитала. 
1. Маркс, К. и Энгельс, Ф. Соч. Т. 23,- С. 178

\section{ЛИТЕРАТУРА}

2. Добрынин А.И. Дятлов С.А. Цыренова Д. Человеческий капитал в транзитивной экономике: формирование, оценка, эффективность использования. СПб., 1999

3. Дятлов, С.А. Основы теории человеческого капитала / С.А. Дятлов. - СПб. 1994

4. Иванченко, И.С. Теория человеческого капитала / Креативная экономика. - 2006.—№ 18.—C. 32

5. Щетинин, В.П. Человеческий капитал и неоднозначность его трактовки / В.П. Щетинин // МЭиМЭ0.— 2001.—№ 12. — С. 42-49

6. «Самое мощное оружие русских — это их образование», -Рональд Рейган о советском образовании. URL: https://xn-—7sblqwdegk2n.xn — p1ai/ news/1677-samoe-moschnoe-oruzhie-russkih-jeto-ih-obrazovanie-ronald-rejgan-0-0ovetskom-obrazovanii.html (дата обращения: 25.10.2021)

7. Греф предлагает радикально изменить модель образования в России. URL: https://tass.ru/obschestvo/2588841 (дата 0бращения: 21.10.2021)

8. Миронов С. Министр образования должен уйти в отставку!: URL: https://www.kp.ru/daily/26549/3565885/ (дата 0бращения: 23.10.2021)

9. Самая большая зарплата — полмиллиона. В Екатеринбурге руководители вузов раскрыли доходы за 2018 год. URL: https://www.znak.com/2019-0528/rukovoditeli_vuzov_ekaterinburga_raskryli_zarplaty_i_dohody_za_2018_god (дата обращения: 25.10.2021)

10. Либералы вступили в битву с Министерством образования за новые стандарты. https://regnum.ru/news/2407371.html (дата 0бращения: 23.10.2021)

11. Ценное признание господина Фурсенко. URL: https://socklgd.ru/article/29-obrazovanie-v-rossii-problemy-i-perspektivy (дата 0бращения: 25.10.2021)

12. Карьеры разошлись с дипломами в разные стороны. https://www.kommersant.ru/doc/4492476 (дата обращения: 25.10.2021)

13. Лишь 30\% выпускников педагогических вузов в России идут работать в школы. URL: https://regnum.ru/news/society/2768732.html (дата обращения: 25.10.2021)

14. Зачем в пединститутах увеличили число бюджетных мест. URL: https://www.ng.ru/education/2021-01-20/8_8061_education1.html (дата 0бращения: 21.10.2021)

(с) Бетанов Владимир Магометович ( v.betanov@yandex.ru ).

Журнал «Современная наука: актуальные проблемы теории и практики»



